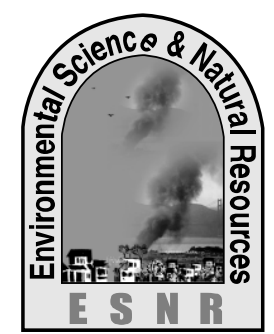

\title{
A Study on Different Brands of Zinc Fertilizers Available in the Markets of Chuadanga Region
}

\author{
G. M. M. Islam ${ }^{1 *}$, S. M. A. Iqbal ${ }^{1}$, M. R. A. Mollah ${ }^{2}$, S. S. Hossain ${ }^{3}$ and M. A. Ali \\ Chowdhury ${ }^{3}$ \\ ${ }^{1}$ Soil Resource Development Institute (SRDI), Jessore, Bangladesh \\ ${ }^{2}$ On- Farm Research Division, BARI, Bogra, Bangladesh \\ ${ }^{3}$ Dept. of Agriculture Extension (DAE), Jhenaidah, Bangladesh \\ *Corresponding author: mesbahsrdi@gmail.com
}

\begin{abstract}
A study was conducted in Damurhuda upazila under Chuadanga district from January to December, 2014 to collect information on names, numbers and comparative availability of different brands of Zinc fertilizers in order to aid the assessment of nutrient status for quality of the brands. For this purpose, information was collected from 30 randomly selected fertilizer shops (10 BCIC fertilizer dealers and 20 retailers) through questionnaire interview. In the study total 80 brands [41 Zinc sulfate (mono), 22 Zinc sulfate (hepta) and 17 Chelated zinc] of zinc fertilizer marketed by 51 companies were found in the upazila. Grogin, Topaz, Zinc Sulfate, Mukta Plus, Zingsul, Hay Zinc ${ }^{+}$of Zinc sulfate (mono) brands, Topaz and Petro zinc of Zinc sulfate (hepta) brands and Brexil, Field Marshal, Topaz of Chelated zinc brands were most available. "Grogin" of Zinc sulfate (mono) and "Topaz" of Zinc sulfate (hepta) were the top most available. Five percent of Zinc sulfate (mono) and nine percent of Zinc sulfate (hepta) mentioned no registration number. No maximum retail price (MRP) was mentioned in seven percent of Zinc sulfate (mono). There was a significant difference between highest and lowest MRP of imported Zinc sulfate (mono) and Chelated zinc brands.
\end{abstract}

Key words: Brand name, Chuadanga, Fertilizer, Zinc

\section{Introduction}

Fertilizer is an essential component in our agriculture. We cannot think our modern agriculture now a days without using chemical fertilizer as our soil resource is being degraded for intensive cultivation of HYV and hybrid variety of different crops. But it is matter of woe that adulteration of chemical fertilizer is being a great problem with time (Anonymous, 2012). SRDI (2014) also reported that about forty per cent urea and non-urea fertilizers available in Bangladesh's market is adulterated and contains highest level of heavy metal that can cause serious health hazards to the people and affect food production and soil fertility in the long run. Moreover, by applying such contaminated fertilizers, farmers are cheated and production suffers. Seventy nine percent Zinc Sulfate (hepta hydrate) fertilizers are adulterated in Jessore region (Islam et al., 2015). Till now at least 109 types of chemical and organic fertilizers are approved by the Government of Bangladesh. Among them twenty four types are open for all and rests are assigned to particular private and non-government organizations for importing and manufacturing (BARC, 2006). BADC (2012) and BCIC (2013) reported that China, Quatar, Soudiarab and Deshi types of Urea fertilizer, Cargil, Australia, China, Morocco and Deshi types of DAP, China, Tunisia, Morocco, Lebanon, Bulgeria and Deshi types of TSP and Canada and Belarush types of MOP are available in our domestic market. In case of micro nutrient fertilizers, three categories of Zinc fertilizer viz. Zinc Sulfate (hepta hydrate), Zinc Sulfate (mono hydrate) and Chelated Zinc and three categories of Boron fertilizer viz. Boric acid, Solubor and Fertibor are approved by the Govt. (DAE, 2014). Many brand names of each of those categories are available in the market. It is necessary to know the comparative availability as well as the individual nutrient status for quality of different brands of three categories of Zinc fertilizer in order to take all types of fertilizer enterprises (manufacturer, supplier and importer) under quality control scheme to ensure the supply of quality fertilizers. But there is no sufficient information about the definite number and name of brand of Zinc fertilizers available in a particular area of the country. Therefore, present study was conducted to find out how many and which brand of Zinc fertilizers are available in the markets of Chuadanga region and to compare the availability of those brands in order to aid the assessment of nutrient status for quality.

\section{Materials and Methods}

The present study was carried out in Damurhuda upazila under chuadanga district during the period from January to December, 2014 to collect the information on the availability of different brand name of Zinc fertilizers. For this purpose investigations were conducted in three points viz. Damurhuda sadar, Darsana and Karpasdanga bazar that were considered as main bazar of the upazila and where dealership of Bangladesh Chemical Industries Corporation (BCIC) were distributed. There were ten BCIC fertilizer dealers in the upazila among which four were at Damurhuda sadar and three were at both Darsana and Karpasdanga bazar. For that reason, information was collected from different fertilizer shops situated on those bazar points and surrounding the points. All BCIC fertilizer dealers were included in the study. Twice of BCIC dealer from each point were considered as the number of retailer shops. Thus 20 retailers with 10 BCIC dealers and total 30 fertilizer shops were taken under the study. Among the retailers, eight were randomly selected from Damurhuda sadar and six from both Darsana and Karpasdanga points. Informations on the number and name of brands of each category of Zinc fertilizer were recorded from each of thirty shops by individual interview. Manufacturer's or supplier's name, Government registration number, maximum retail price (MRP) and date of expiry (DOE) of each brand were 
also recorded during interview. Data were collected through questionnaire interview. The questionnaire prepared in Bengali was designed with both closed and open form of questions. The collected data were coded, summarized and proceed for analysis. Qualitative data were converted into quantitative forms by means of suitable scoring technique whenever necessary. Tabulations and cross tabulations were done on the basis of categorization developed by the researcher. Tabular technique was applied for the analysis of data by using simple statistical tools like averages and percentages. Selected 30 shops were assumed as 30 attendance for each brand. One mark (score point) was given for each attendance in a shop against a brand and total score point (TSP) was calculated with the aggregate of the score points for the individual (i.e. TSP 2 means the brand was present in 2 shops out of 30 shops). TSP of a brand represented its degree of presence which were treated as its availability. Then they were tabulated gradually from highest to lowest depending on their TSP. Finally they were classified into following three classes depending on the availability.

Table 1. Availability class and their range of total score points (TSP) of different category of Zinc fertilizer.

\begin{tabular}{|l|c|c|c|}
\hline \multirow{2}{*}{ Availability Class } & \multicolumn{3}{|c|}{ Total score point (TSP) Obtained } \\
\cline { 2 - 4 } & Zinc sulfate (mono) & Zinc sulfate (hepta) & Chelated zinc \\
\hline Most available: Class-I & $>4$ & $>4$ & 3 \\
\hline Moderately available: Class-II & $2-4$ & $2-4$ & 2 \\
\hline Less available: Class-III & $<2$ & $<2$ & $<2$ \\
\hline
\end{tabular}

\section{Results and Discussion}

\section{Brand name and availability}

Total 80 brands [41 of Zinc sulfate (mono), 22 of Zinc sulfate (hepta) and 17 of Chelated zinc] were found in the market of Damurhuda upazila which were manufactured or marketed by 51 individual company. Table 2 shows the Brand names of different categories of zinc fertilizer including their availability class. In case of Zinc sulfate (mono), 6 brands included class-I among which only the "Grogin" obtained the total score point (TSP) 10 and another one "Topaz" obtained 8 points. "Zinc Sulfate", "Mukta Plus", "Zingsul”, "Hay Zinc +" this four brands obtained 5 points each. This indicated that above mentioned six brands of Zinc sulfate (mono) were most available in the market among which the brand Grogin (Registration number: IMP-959; marketed by Syngenta Bangladesh Ltd.) was the top most available brand. Eleven brands included class-II among which two brands "Star Plus" and "Mac Zinc gold" obtained 3 points and another nine brands American Zinc, Eon Zinc, Soktiman, Mim Zinc, Sokti plus, Alfa Zinc, Limi Zinc, Super Zinc (M-1816), New Shakti plus obtained 2 points. That means this 11 brands were moderately available in the market. The rest 24 brands under class-III [Bumper Mono Zinc, Bumper Mono Gold, Super Zinc (IMP-958), Tara, Mukta Dosta, American Grogin, Suphala, Wangsheng Zinc, American Gold, American Zingsul, Bless Zinc, Zinc Plus, American Zinc Sulfate, Total Zinc, Fine Zinc, American gold Royal Zinc, Map Zinc, Agro Fresh, Groginc plus, Chaka Zinc, Groginc gold, American Zinc gold, Action Zinc, Penguin] obtained 1 score point that were considered as less available. In case of Zinc sulfate (hepta), 2 brands included class-I among which Topaz obtained highest 6 points and Petro zinc obtained 5 points. This indicated that this 2 brands were the most available among which the brand Topaz (Registration number: IMP-1488; marketed by Intefa Ago Industries Ltd.) was the top most available brand. Subsequently, only "Alfa zinc" under class-II was moderately available for obtaining 2 points. And another 19 brands
(Hepta Zinc, Suphala Zinc, Suphalon, Soktiman, Top, Zinc plus, Mum Zinc, Sokti, Krishan-G, Lima Zinc, Fine Zinc, Ankur Zinc, Auto Zinc, Krishi Zinc, Bahi Zinc, Ashia Zinc, Penguin, Pusti plus, Taza Zinc) under class-III were considered as less available brands. Further, in case of Chealeted zinc, each of 3 brands (Brexil Zinc, Field Marshal Zinc, Topaz Chelated) under class-I obtained 3 points and considered as most available. "Chili zinc" and "Chela zinc" under class-II were moderately available and rest 12 brands (Zingsul, Librel, Volt, Chilakor, Zinc-C, Super Zinc, Zinga 15 plus, King Zinc, Ankur zinc, Limi Zinc, Mac Chili, Glory gold) obtaining 1score point might be considered as less available brands of Chelated zinc fertilizer. Therefore, 11 brands [ 6 of Zinc sulfate (mono), 2 of Zinc sulfate (hepta), and 3 of Chelated zinc] were most available, 14 brands were moderately available and rest 55 brands were less available in the market of Damurhuda upazila for farmers. So their quality should be analyzed with great importance.

\section{Maximum retail price (MRP)}

Maximum retail price (MRP) of imported Zinc sulfate (mono) fertilizer varied from TK.160 (Mukta dosta; IMP-3322) to 230 (Zinc plus; IMP-51) $\mathrm{kg}^{-1}$ and that of supplied and manufactured one varied from TK.180 (American Zingsul; S-1139) to 198 (Alfa zinc; S-29) and TK.175 (Super zinc; M-1816) to 180 (Shokti plus; M-264) kg-1 respectively. Suphala (Reg. number Nil) marketed by Suphala Agro chemical Ind., Dhaka, Grozinc plus (Reg. number Nil) marketed by Green Agro Ltd. Dhaka and American zinc gold (IMP-2180) Zinc sulfate (mono) marketed by Land crop care , Dhaka mentioned no MRP. All Zinc sulfate (hepta) and Chelated zinc mentioned their MRP. Different brands of Zinc sulfate (hepta) ranged from TK.105 (Suphala) to 161 (Alfa zinc) $\mathrm{kg}^{-1}$ in their MRP among which imported, supplied and manufactured fertilizer varied from Tk.115 (Zinc plus; IMP-1094) to 150, 145 (Pusti plus; S-2571) to 161 (Alfa Zinc; S-99) and 105 
(Suphala; M-19) to 155 (Taza Zinc; M-374) $\mathrm{kg}^{-1}$, respectively. In case of Chelated zinc, all 17 fertilizers are imported item. Their MRP varied from TK.1470
(Volt; IMP-3054) to 3820 (King zing; IMP-1261) $\mathrm{kg}^{-1}$ fertilizer (they are available in 17 and 20 gram packet).

Table 2. Brand names of different categories of zinc fertilizer including their availability class.

\begin{tabular}{|c|c|c|c|c|}
\hline $\begin{array}{c}\text { Category of Zinc } \\
\text { Fertilizer }\end{array}$ & $\begin{array}{c}\text { Availability } \\
\text { Class }\end{array}$ & TSP & Name of brands & $\begin{array}{c}\text { Number } \\
\text { of } \\
\text { brand }\end{array}$ \\
\hline \multirow[t]{6}{*}{ Mono } & \multirow[t]{3}{*}{ Class-I } & 10 & Grogin. & 01 \\
\hline & & 8 & Topaz. & 01 \\
\hline & & 5 & Zinc Sulfate, Mukta Plus, Zingsul, Hay Zinc +. & 04 \\
\hline & \multirow[t]{2}{*}{ Class-II } & 3 & Star Plus, Mac Zinc gold. & 02 \\
\hline & & 2 & $\begin{array}{l}\text { American Zinc, Eon Zinc, Soktiman, Mim Zinc, Sokti plus, } \\
\text { Alfa Zinc, Limi Zinc, Super Zinc (M-1816), New Shakti plus. }\end{array}$ & 09 \\
\hline & Class-III & 1 & $\begin{array}{l}\text { Bumper Mono Zinc, Bumper Mono Gold, Super Zinc (IMP- } \\
\text { 958), Tara, Mukta Dosta, American Grogin, Suphala, } \\
\text { Wangsheng Zinc, American Gold, American Zingsul, Bless } \\
\text { Zinc, Zinc Plus, American Zinc Sulfate, Total Zinc, Fine Zinc, } \\
\text { American gold Royal Zinc, Map Zinc, Agro Fresh, Groginc } \\
\text { plus, Chaka Zinc, Groginc gold, American Zinc gold, Action } \\
\text { Zinc, Penguin. }\end{array}$ & 24 \\
\hline \multirow[t]{4}{*}{ Hepta } & \multirow[t]{2}{*}{ Class-I } & 6 & Topaz. & 01 \\
\hline & & 5 & Petro Zinc. & 01 \\
\hline & Class-II & 2 & Alfa Zinc. & 01 \\
\hline & Class-III & 1 & $\begin{array}{l}\text { Hepta Zinc, Suphala Zinc, Suphalon, Soktiman, Top, Zinc } \\
\text { plus, Mum Zinc, Sokti, Krishan-G, Lima Zinc, Fine Zinc, } \\
\text { Ankur Zinc, Auto Zinc, Krishi Zinc, Bahi Zinc, Ashia Zinc, } \\
\text { Penguin, Pusti plus, Taza Zinc. }\end{array}$ & 19 \\
\hline \multirow[t]{3}{*}{ Chelated zinc } & Class-I & 3 & Brexil Zinc, Field Marshal Zinc, Topaz Chelated. & 03 \\
\hline & Class-II & 2 & Chili Zinc, Chela Zinc. & 02 \\
\hline & Class-III & 1 & $\begin{array}{l}\text { Zingsul, Librel, Volt, Chilakor, Zinc-C, Super Zinc, Zinga } 15 \\
\text { plus, King Zinc, Ankur zinc, Limi Zinc, Mac Chili, Glory gold. }\end{array}$ & 12 \\
\hline
\end{tabular}

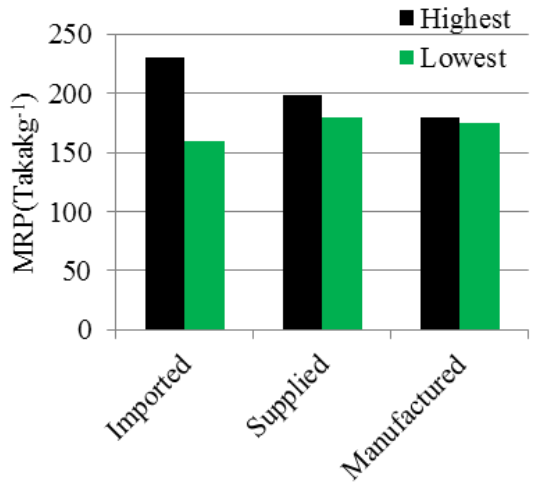

Fig.1. Highest and lowest MRP of Zinc Sulfate (mono)

There was a significant difference between highest and lowest MRP of imported Zinc sulfate (mono) fertilizer (Fig.1). Highest price was $43 \%$ more than lowest one. Lower MRP of same type of product might result adulteration. Price of supplied and manufactured type was more or less nearly. In case of Zinc sulfate (hepta), a mentionable difference was observed between highest and lowest MRP of imported (highest was 30\% more than lowest) as well as manufactured type (highest was $48 \%$ more than lowest). But those of supplied one fertilizer were more or less nearly (Fig.2). Further, a

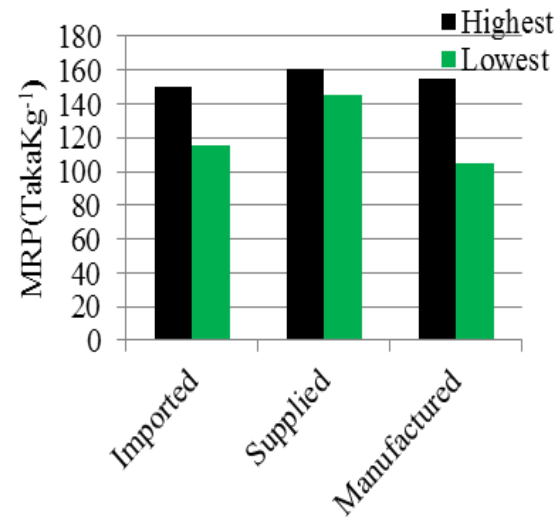

Fig. 2. Highest and lowest MRP of Zinc Sulfate (hepta)

wide difference (160\%) was conspicuously observed in highest and lowest MRP of imported types of Chelated zinc (Fig. 3). According to Government specification of fertilizer, Zinc sulfate (mono), Zinc sulfate (hepta) and Chelated zinc must have minimum 36, 21 and 10 percent total zinc respectively. It is also mandatory to have minimum $17.5 \%$ sulfur in Zinc sulfate (mono) and $10.5 \%$ sulfur in Zinc sulfate (hepta). Chelated is Sulfur free fertilizer and it is used as foliar spray which is more useful for plant (FRG, 2012). 


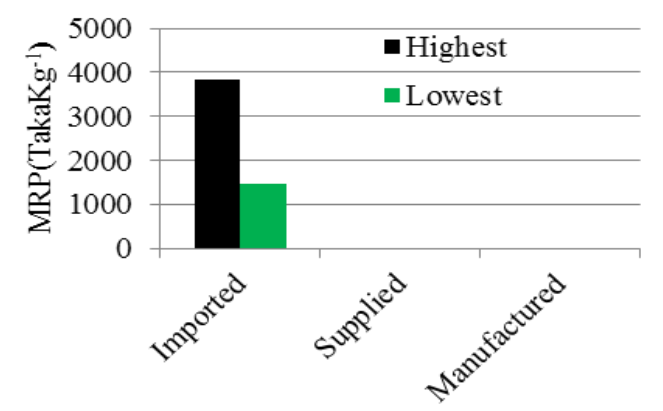

Fig. 3. Highest and lowest MRP of Chelated Zinc

Fig. 4 shows the comparative average MRP of different types (imported, supplied and manufactured) of Zinc sulfate (mono), Zinc sulfate (hepta) and Chelated zinc. In case of Zinc sulfate (mono) committed to have $36 \%$ $\mathrm{Zn}$ and $17.5 \% \mathrm{~S}$, average MRP of imported, supplied and manufactured type were 186, 189 and 178 taka kg-1 respectively. On the other hand In case of Zinc sulfate (hepta) committed to have $21 \% \mathrm{Zn}$ and $10.5 \% \mathrm{~S}$, MRP of those were 135,153 and 133 taka kg-1 irrespective of three types. But that price of Chelated zinc was 2,350 taka kg-1 that was very much absurd and such higher price perhaps might be for its distinction. Therefore, their chemical analyses for quality is very important to see the actual scenario.

\section{Registration features}

Total 80 brands of zinc fertilizer were found in the upazila. Three types of registration number were observed against the brands mentioned on their packets.

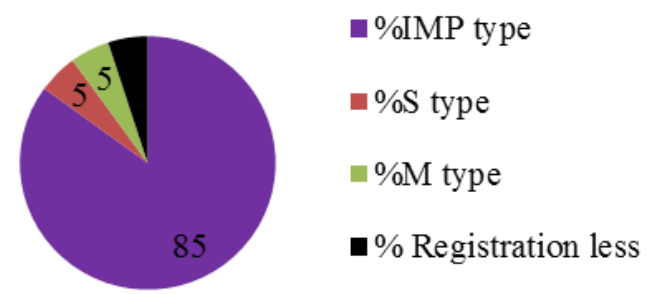

Fig. 5. Relative proportions of different types of registration number in Zinc sulfate (mono)

\section{Company characteristics}

Fifty one companies marketed eighty brands of zinc fertilizer. Forty one brands of Zinc sulfate (mono), twenty two brands of Zinc sulfate (hepta) and seventeen brands of Chelated zinc were marketed 38, 21 and 17 companies respectively. In case of Zinc sulfate (hepta), additional nine companies were found over Zinc sulfate (mono) companies. Further, additional four companies were found over forty seven of Zinc sulfate (mono) and Zinc sulfate (hepta) company in case of Chelated zinc. Each of ACI Agro Ltd., Dhaka and Priya Agro Ind., Dhaka marketed two Zinc sulfate (mono) brands using same registration number (IMP-1234 of ACI Agro Ltd., Dhaka and IMP-1858 of Priya Agro Ind., Dhaka). Accordingly, Krishi crop care, Dhaka marketed both Auto Zinc (IMP-1143) and Krishi Zinc (IMP-1144) brand of Zinc sulfate (hepta). Except that, each

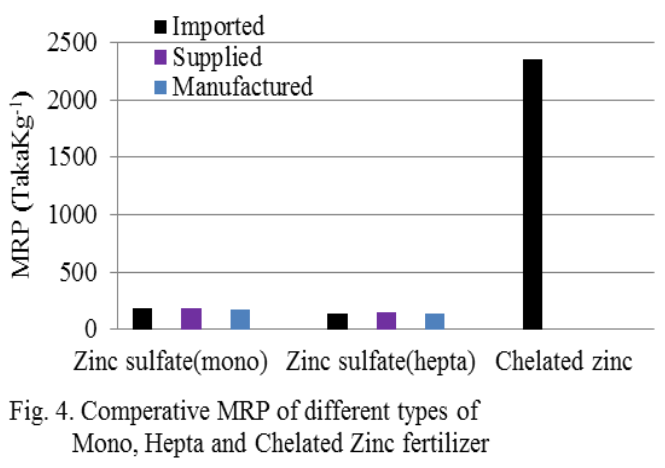

They were namely "IMP", "S" and "M" type. According to registration certificate issued by the Govt., "IMP" means imported from aboard, "S" means supplied by purchasing from importer or manufacturer and "M" means manufactured locally in their own factory (DAE, 2014). Five and nine percent of Zinc sulfate (mono) and Zinc sulfate (hepta) respectively mentioned no registration number. But all the brands of Chelated zinc mentioned their registration numbers. Fig. 5 shows that $85 \%$ of mono brands were imported and both supplied and manufactured types covered $5 \%$. But in case of Zinc sulfate (hepta) brand, 55\%, 9\% and $27 \%$ were imported, supplied and manufactured types respectively (Fig. 6). All Chelated zinc brands bore imported type registration number which were imported from aboard by seventeen different companies The brands without any registration number might be adulterated. So category wise quality analysis of zinc fertilizer is necessary.

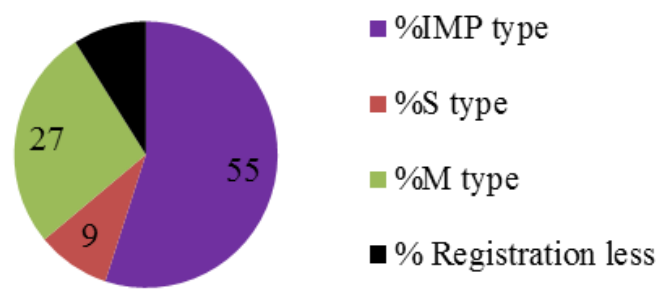

Fig. 6. Relative proportions of different types of registration number in Zinc sulfate (hepta)

company marketed only one individual brand. All the companies were of several types depending on their address. Eighty two percent were of Dhaka based and Eighteen percent were of out of Dhaka based among which 6, 4, 4, 2 and 2 percent were of Jessore, Jhenaidah, Chuadanga, Meherpur and Narsingdi respectively. Among the companies, 59\% marketed only one category of zinc fertilizer [35\% company provided only Zinc sulfate (mono), $16 \%$ provided only Zinc sulfate (hepta) and $8 \%$ company provided only Chelated zinc]. On the other hand, 29\% company marketed two categories [Zinc sulfate (mono) and Zinc sulfate (hepta) $13 \%$, Zinc sulfate (mono) and Chelated zinc $13 \%$ or Zinc sulfate (hepta) and Chelated zinc $3 \%$ ] and $10 \%$ companies marketed all three categories of zinc fertilizer. 


\section{Conclusions}

Total eighty zinc fertilizer brands manufactured or marketed by fifty one individual company were found in the market of Damurhuda upazila among which 11 brands [6 of Zinc sulfate (mono), 2 of Zinc sulfate (hepta) and 3of Chelated zinc] were most available, 14 were moderately and 55 were less available. According to Fertilizer (management) Act-2006 of Government of Bangladesh, the product without registration number and MRP on their packet is not allowed to market. But this study found $5 \%$ of Zinc sulfate (mono) and $9 \%$ of Zinc sulfate (hepta) were registration number less and $7 \%$ of Zinc sulfate (mono) were MRP less brand in the market. In that case, the company was in a wrong practice in their business. The brands without any

\section{References}

Anonymous, 2012. Annual Report of 2011-2012, Soil Resource Development Institute, Min. Agric., GoB. Farmgate, Dhaka.

BARC (Bangladesh Agricultural Research Council), 2006. List of Fertilizer and Fertilizer commodities: 1995-2006. Min. Agric., Govt. Peoples Repub. Bangladesh. pp. 36-74.

BADC (Bangladesh Agricultural Development Corporation), 2012. Fertilizer Imported by Bangladesh Agricultural Development Corporation. Min. Agric., GoB. Dilkusha, Dhaka.

BCIC (Bangladesh Chemical Industries Corporation), 2013. Report on Imported Fertilizers. Ministry of Industry and Commerce, GoB. Motijheel, Dhaka. registration number might be adulterated. Remarkable variation was observed among the MRP of the brands of each category. On the other hand, MRP of Chelated zinc was too much higher than Zinc sulfate (mono) and Zinc sulfate (hepta). Beside this, a wide difference $(160 \%)$ was conspicuously observed in highest and lowest MRP of Chelated zinc fertilizer. Lower MRP of same type of product might cause adulteration also. So chemical analyses for quality of all category of zinc fertilizer is very much important to see the actual scenario. However, the study suggests that (a) illegal company should be taken under regulation and (b) further study is needed to assess the individual quality status of all the brands of three categories of zinc fertilizer obtained in this study.

DAE (Department of Agriculture Extension), 2014. List of Import registration certificate holder. Dept. Agric, Extn., Farmgate, Dhaka. pp.23-74.

FRG (Fertilizer Recommendation Guide), 2012. Bangladesh Agricultural Research Council, Farmgrate, Dhaka-1215.274p.

Islam, G. M. M.; Hossain, M; Iqbal, S. M. A. and Mollah, M. R. A. 2015. Assessment of quality status of Zinc Sulfate (Hepta hydrate) fertilizers available in the markets of Jessore Sadar Upazila. J. Environ. Sci. \& Natural Resources, 8(1): 69-71.

SRDI (Soil Resource Development Institute), 2014. Annual Report of 2012-2013, Soil Resource Development Institute. Farmgate, Dhaka. 